\title{
Política de derechos-política de "bien común". Tres críticas posibles al comunitarismo
}

\author{
GUSTAVO FONDEVILA \\ Instituto de Investigaciones Filosóficas \\ Universidad Nacional Autónoma de México \\ fondevil@filosoficas.unam.mx
}

\begin{abstract}
Resumen: En este trabajo se hace una presentación general del comunitarismo y posteriormente se discuten tres críticas al "comunitarismo integracionista" según la distinción de Sheila Benhabib. Esta posición teórica desarrolla un determinado programa político como alternativa a la fundamentación tradicional del Estado de derecho liberal que puede resumirse en la propuesta de repolitizar el Estado basándose en una política de lealtad-servicio-civilidad-tolerancia y participación ciudadana. Las críticas están formuladas contra el papel que la comunidad, el contexto y lo contingente, y el "bien común" desempeñan en esa propuesta política.
\end{abstract}

Palabras clave: liberalismo, republicanismo, comunidad, participación

El término communitarianism fue concebido como una marca para las críticas filosóficas al liberalismo que comenzaron a dominar la teoría política en Estados Unidos durante la década de 1980. En particular, los trabajos filosóficos de Benjamin Barber (democracia participativa), Michael Sandel (ontología de la comunidad), Alasdair MacIntyre (filosofía de la virtud), Charles Taylor (antropología hermenéutica) y Michael Walzer (teoría particularista de la justicia), y los trabajos sociológicos de Robert Bellah y William Sullivan (bases republicanas de Estados Unidos) fueron los que rápidamente recibieron ese título que se convirtió en la marca de una parte de los polémicos debates entre John Rawls, que en 1971 había rejuvenecido la teoría liberal con su Teoría de la justicia, y sus críticos y opositores. Las fuentes habituales del comunitarismo ${ }^{1}$ son el neoaristotelismo, Hegel y su crítica a Kant centrada en la idea de la "eticidad sustancial", o la tradición del "republicanismo cívico", cuyos antecedentes son Aristóteles y Rousseau.

Posteriormente, el comunitarismo adquirió relieve filosófico y peso político propio, y en muchos casos sirvió directamente para inspirar políticas de gobierno o, al menos, discursos de campaña, y explicar acontecimientos políticos y sociales de importancia. ${ }^{2}$ Amitai Etzioni promovió en Gran Bre-

${ }^{1}$ Cfr. A. Gutmann, "Communitarian Critics to Liberalism", pp. 308 y ss.

${ }^{2}$ Por ejemplo, la campaña presidencial de 1992 en Estados Unidos abundó en temas típicamente comunitaristas con frecuentes llamados al "sentido comunitario y la recuperación de valores ciudadanos". Algunos autores comunitaristas participaron en movimientos ciudadanos 
taña lo que denominó "movimiento comunitarista", que fue inaugurado en Estados Unidos con la redacción, en 1991, de un Bill of Rigths and Responsibilities y la fundación de un periódico titulado The Responsive Community. Setenta políticos, académicos y figuras cívicas del espectro político estadounidense firmaron la Communitarian Platform, aunque ninguno de los filósofos comunitaristas más importantes la suscribieron. ${ }^{3}$ Posteriormente, el libro de Etizioni, The Spirit of Community, ${ }^{4}$ cruzó el Atlántico y fue adoptado por los defensores del llamado Third Way. ${ }^{5}$ Hoy en día, el llamado a los valores comunitarios, el reempowerment de la sociedad civil y la retirada del Estado social forman parte habitual también del discurso de la socialdemocracia europea. ${ }^{6}$ En el terreno de la filosofía, de las ciencias sociales y de la teoría política, el comunitarismo también ganó en importancia y extensión internacional. Si bien hasta hace pocos años los comunitaristas estadounidenses eran absolutamente desconocidos en la escena intelectual europea, en la actualidad, esa situación ha cambiado. En Alemania, por ejemplo, sería casi imposible en este momento que hubiera una revista teórica o seminario sociológico o filosófico que no mencionase el debate comunitarista. Posiblemente, desde la controversia entre Habermas y Luhmann en los años setenta y la querelle franco-alemana sobre la crítica de la razón posmoderna en los años ochenta, no haya en la filosofía social alemana actual una discusión tan importante como la generada por los comunitaristas. ${ }^{7}$ Esto posiblemente tenga que ver no sólo con la recepción que se hizo del comunitarismo, sino también con las características propias de la tradición. Gracias a Ferdinand Tönnies, existe en dicha filosofía social una larga costumbre de distinguir entre Gemeinschaft (comunidad) y Gesellschaft (sociedad) como dos categorías que describen formas distintas de integración social. Esta distinción abrió el camino para un análisis del proceso de modernización social enfocado en la creciente descomposición

o en organizaciones civiles no gubernamentales. Cfr. W. Reese-Schäfer, Was ist Kommunitarismus, pp. 7-12.

${ }^{3}$ MacIntyre, en particular, ha señalado en muchas ocasiones la necesidad de disolver el Communitarian Label, cuyas aplicaciones políticas son inconsistentes. Cfr. F. Bowring, "Communitarianism and Morality: In Search of the Subject", pp. 96-97. En realidad, el término "comunitarismo" se emplea en la bibliografía secundaria. Solamente Michael Sandel y el brazo político del "movimiento" reunido en torno al economista Etzioni lo usan para referirse a sí mismos. Cfr. M. Sandel, Liberalism and Its Critics, pp. 1-5.

${ }^{4}$ Cfr. A. Etzioni, The Spirit of Community, y New Communitarian Thinking.

${ }^{5}$ Cfr. T. Blair, New Britain: My Vision of a Young Country, p. 206: "esa filosofía comunitarista [...] nos permite ir más allá de la alternativa entre el individualismo estrecho y el socialismo de la vieja guardia". Otros dirigentes, como Gordon Brown, Paddy Ashdown y David Willetts, expresaron su interés y su acuerdo con el llamado de Etzioni a una "moratoria en la acuñación de nuevos derechos y al restablecimiento de un código moral estricto" (ibid., p. 209).

${ }^{6}$ Cfr. Tagesspiegel, 23 de mayo de 1999, p. 8.

${ }^{7}$ Cfr. O. Kallscheuer, "Kommunitarismus? Anregungen zum weiterlesen”, prólogo, pp. 124 125. 
de las relaciones comunitarias que promueve la pérdida de solidaridad. ${ }^{8} \mathrm{La}$ idea general es que la existencia de los seres humanos depende de comunidades éticamente integradas y que el proceso de modernización destruye los lazos de los individuos con su comunidad y pone en peligro las formas tradicionales de la vida comunitaria. La tesis principal del comunitarismo tiene que ver con la recuperación del punto de vista de la comunidad para analizar los problemas sociales de las sociedades postindustriales, y por eso pudo tener una rápida incorporación a la discusión. El ideal es una comunidad en la cual los miembros se relacionen entre sí, no a través de relaciones jurídicas, sino mediante orientaciones y valoraciones éticas comunes. El diagnóstico se centra en un proceso de modernización que erosiona profundamente los lazos sociales que los seres humanos guardan unos con otros en el interior de una sociedad. Esto no se diferencia demasiado del análisis de Weber, Durkheim o Simmel, quienes ya habían descrito el pasaje a la modernidad como un proceso de extracción del sujeto de las formas sociales previas.

En resumen, las tesis principales del comunitarismo apuntan a los procesos de desintegración social que se dan en las sociedades postindustriales. La idea central es que una sociedad que quiera fundarse en individuos que se encuentren aislados unos de otros, atomizados y que sólo persigan sus propios intereses, socava sus propios fundamentos. La concepción liberal, que en su momento tuvo consecuencias liberadoras frente al viejo orden jerárquico medieval, desactiva en la actualidad toda forma de compromiso ciudadano y desalienta el desarrollo de la virtud ciudadana. Entre las consecuencias de esto están la apatía cívica, la pérdida de identidad nacional, la caída en la legitimidad del sistema político y de las instituciones públicas, etcétera.

Casi todos los autores comunitaristas consideran en menor o mayor medida que el proceso de modernización ha tomado en la actualidad la forma de un proceso de fragmentación; es decir, un individualismo agudo que destruye los lazos sociales de integración de los individuos a su familia, a su comunidad, a su grupo de pertenencia, a su Estado, a su nación, etc. Las consecuencias negativas de este proceso se dan en todos los órdenes de la vida social. Se trata de una crítica dirigida al liberalismo, que presupone que la sociedad ideal es una sociedad absolutamente disgregada donde los individuos son una especie de átomos libres que celebran contratos, van al mercado a satisfacer sus necesidades y recurren a la política para defender sus ámbitos de libertad de acción —una concepción en la cual los individuos anteceden a la sociedad misma y no necesitan demasiado de ella para la formación de su identidad individual.

${ }^{8}$ Cfr. A. Honneth, "Individualisierung und Gemeinschaft", pp. 16-17. 
En términos generales, es posible establecer una diferencia entre posiciones "integracionistas" y "participativas". ${ }^{9}$ Esta clasificación realizada por Benhabib distingue un comunitarismo (integracionista) que sostiene que la única solución para la anomia de las sociedades postindustriales es la revitalización de valores sustanciales mediante un auténtico proceso de resocialización "comunitario" y el rechazo de la diferenciación social. La atención debe estar dirigida a la protección de la integridad de los vínculos comunitarios y no, como en las sociedades liberales, a la protección de los derechos y libertades individuales. La vertiente participativa del civic republicanism acepta los conflictos del pluralismo social y no comparte la nostalgia republicana del integracionismo. ${ }^{10}$ La sociedad es concebida como un horizonte valorativo, una esfera pública de participación ciudadana. ${ }^{11}$

En este trabajo se restringe el análisis a la posición integracionista que desarrolla un determinado programa político como alternativa a la fundamentación tradicional del Estado de derecho liberal. Las modalidades propuestas de comprensión de la política se corresponden cum grano salis con tres formas de ciudadanía distintas. ${ }^{12}$

1. El ciudadano oprimido. No recibe protección adecuada del Estado, ya sea bajo la forma de protección de su vida, de su libertad, de su propiedad o de su bienestar (welfare), aunque puede participar políticamente.

2. El ciudadano alienado. Recibe protección del Estado y vive su vida junto a los otros ciudadanos a la sombra de esa protección; pero no participa en la vida política por decisión propia. Ve al Estado como algo ajeno a su mundo, pero no como una fuerza hostil.

3. El ciudadano pluralista. Recibe protección del Estado y participa activamente en el proceso de gobernar y ser gobernado. Esta ciudadanía implica un estatus moral más que un estatus legal. Es un ciudadano que se encuentra socialmente integrado y compelido a obedecer la ley, sin sentir ninguna tensión entre la responsabilidad política y la privacidad personal.

Esta última forma hace referencia al autogobierno de los ciudadanos generado a través de grupos que no pertenecen al Estado y que desempeñan un

\footnotetext{
${ }^{9}$ Véase S. Benhabib, "Autonomy, Modernity, and Community. Communitarianism and Critical Social Theory in Dialogue".

${ }^{10}$ Cfr. B. Barber, The Conquest of Politics, p. 177.

${ }^{11}$ Cfr. B. Barber, Strong Democracy. Participatory Politics for a New Age, pp. 31, 100, 104, 122 , 142, 152, 219. Esta posición tiene algunas similitudes con el republicanismo del constitucionalismo estadounidense. Véanse F. Michelmann, "Laws Republic", p. 1493; C.R. Sunstein, "Beyond the Republican Revival", p. 1539. Y también con la idea de política deliberativa de Habermas. Cfr. J. Habermas, Faktizität und Geltung, especialmente la p. 349.

${ }^{12}$ Cfr. M. Walzer, Obligations. Essays on Disobedience, War and Citizenship, pp. 226-228.
} 
papel informal, a veces oficial, en la determinación de la política estatal. La participación en el modelo pluralista es un proceso indirecto hecho posible por la participatory politics (política de participación) de grupos civiles, como iglesias, sindicatos, asociaciones vecinales, etc. Dichos grupos no sólo preparan a los individuos para la ciudadanía, sino que realizan en forma directa derechos y responsabilidades implícitas. Esa función de mediación tiene efectos directos en la integración social de la comunidad. Las instituciones comunitarias generan obligaciones reales y auténtico patriotismo porque representan una esfera donde la acción política en el nivel del ciudadano común puede tener un sentido significativo; además, conforman una red de protección y una forma posible de autodeterminación dentro del Estado. Esta ciudadanía ideal tiene algunas características fundamentales: ${ }^{13}$

\section{Lealtad-servicio-civilidad}

- Los ciudadanos deben tener cierto grado de commitment (compromiso) o lealtad que debe ser simbolizada y sostenida públicamente.

- Deben estar dispuestos a sacrificar sus propios intereses en virtud de la república, defenderla en casos extremos y dar la vida por ella; por ejemplo, en una guerra.

- Se debe obedecer la ley y mantener un tipo especial de decoro y de conducta, es decir, de civilidad. La "buena conducta" debe entenderse nuevamente como la obediencia cotidiana de la ley, dado que las sociedades contemporáneas requieren un alto grado de disciplina social.

2. Tolerancia-participación

- La tolerancia es una forma social de la civilidad. No se trata de una tolerancia que se restringe al ámbito religioso o político, sino que debe extenderse a toda la esfera social.

- El republicanismo es una forma de autogobierno colectivo y su buen funcionamiento requiere la participación política directa de la ciudadanía. ${ }^{14}$

Estas virtudes son importantes para la coordinación de la acción social dado que reducen el conflicto y la tensión, y, en última instancia, preparan el camino para la integración social. Sin embargo, no tiene sentido real hablar de construir cohesión y entusiasmo político desde arriba (from above), usando los mecanismos tradicionales del Estado. Sólo es posible

${ }^{13}$ Cfr. M. Walzer, "Civility and Civic Virtue in Contemporary America".

${ }^{14}$ Ibid. 
una regeneración del tejido social a través de una modificación de los mecanismos políticos tradicionales y una expansión de la esfera pública, es decir, el desarrollo de una política de participación que conlleva:

1. Una democratización radical de las corporaciones gubernamentales. Esto significa trasladar la dimensión de la toma de las decisiones económicas a la esfera pública y convertir esas decisiones en parte habitual de la discusión de los asuntos públicos.

2. Una descentralización de la actividad gubernamental. Se debe alterar la escala habitual de la vida política y aumentar el número de ciudadanos capaces de tener un papel efectivo en la toma de decisiones diaria de la política.

3. La creación de partidos y movimientos sociales que puedan operar en diferentes niveles de gobierno y puedan generar un grado mayor de compromiso individual que los actuales partidos nacionales.

Este programa político alternativo de expansión de la esfera pública sólo se puede realizar a través de una new politicizing (re-politización) del Estado, basada en el reforzamiento institucional de la sociedad civil, el restablecimiento de la solidaridad y la reformulación de las funciones tradicionales del Estado (sobre todo, los programas sociales). Este amplio programa (solidaridad-sociedad civil-reducción del Estado social) se basa en una concepción deontológica determinada de la política y del derecho que tiene como base una determinada concepción de la comunidad, del contexto (lo contingente) y del bien común. Cada uno de estos conceptos tiene una función distinta dentro del programa político.

La finalidad de este trabajo es criticar cada una de estas funciones. La tesis es que asumir el programa comunitarista implica descartar el análisis de las estructuras normativas internas de una sociedad a través de un discurso de fundamentación racional. Esto llevaría al abandono de la idea de un sistema jurídico racional, dado que los ideales jurídicos establecidos bajo la forma de principios ya no deben satisfacer las exigencias de una razón práctica de tipo procedimental. ${ }^{15}$ Y por lo tanto, la propuesta comunitarista no sirve como alternativa a la fundamentación normativa tradicional del Estado de derecho liberal basada en una política de derechos. ${ }^{16}$

\footnotetext{
${ }^{15}$ Cfr. B. Peters, Rationalität, Recht und Gesellschaft, p. 272.

${ }^{16}$ No se discute aquí si el Estado de derecho puede lograr el reconocimiento de principios fundantes mediante la mera corrección valorativa de los mismos. Cfr. R. Dworkin, Laws Empire, p. 195, y "Liberal Community", p. 479.
} 


\section{La función de la comunidad}

Problema: La base antropológica de la filosofía social de corte liberal está concebida en términos individualistas.

Tesis comunitarista: Es imposible pensar a los hombres fuera del marco de sus comunidades. Las mismas tienen una función esencial en la formación de la identidad humana.

Esta tesis reúne en general a todos los pensadores comunitaristas. La idea es que el "yo" debe obligatoriamente formular su identidad moral en el marco de su pertenencia a una comunidad. ${ }^{17}$ Por ejemplo, para Taylor, la idea del "yo" como un actor responsable implica un sujeto capaz de hacer valoraciones a través de ciertos "valores fuertes" que le permiten interpretar su propia vida como un todo unificado ${ }^{18}$ y no como una fragmentación de momentos. Pero es ingenuo pensar que esas formas de valorar pueden ser elegidas libremente por los individuos. En realidad, pertenecen a un ámbito determinado de lenguaje, es decir, a una comunidad lingüística propiamente dicha, donde se generan y reproducen. Esa comunidad significa una forma concreta de vida que determina un horizonte valorativo. El mundo del "yo" es una historia precisa y una forma de vida. Esas comunidades constituyen un marco de comprensión del mundo y autocomprensión cognitiva y normativa. De este modo, a partir de la noción wittgensteiniana de la imposibilidad de los lenguajes privados se deriva que la identidad moral depende de las formas concretas de existencia de la comunidad. ${ }^{19}$

Pero probablemente sea Michael Sandel quien haya dedicado el mayor esfuerzo a criticar el individualismo en la teoría liberal, para llegar a sostener que toda teoría jurídica o ética que proponga la preeminencia de ciertos principios básicos universales de justicia (o derechos individuales), en contraposición a las representaciones comunitarias de lo "bueno", conduce inevitablemente a un individualismo estéril en el que los sujetos se presentan en forma "aislada" y voluntarista. ${ }^{20}$ Este autor pone especial énfasis en la Teoría de la justicia de John Rawls ${ }^{21}$ y afirma que su antropología filosófica está basada en un "yo" radicalmente libre que elige sin ataduras sus intereses, sus necesidades y aun su propia identidad sin prestar atención a ningún vínculo en particular. Este individuo a partir del cual se deriva el contrato de los principios básicos de justicia institucional resulta

${ }^{17}$ Cfr. A. MacIntyre, After Virtue, p. 295.

${ }^{18}$ Cfr. C. Taylor, "What is Human Agency?", p. 15; y "Self-Interpreting Animals", p. 45.

${ }^{19}$ Cfr. C. Taylor, Sources of the Self: The Making of the Modern Identity, pp. 26, 35, 40, 47; y Hegel and Modern Society, p. 157. Taylor aprovecha la filosofía de los juegos de lenguaje de Wittgenstein para reconstruir en términos comunitaristas la idea de "eticidad sustancial" de Hegel.

${ }^{20}$ C. Taylor, Hegel and Modern Society, pp. 1 y 156.

${ }^{21}$ M. Sandel, Liberalism and the Limits of Justice. 
ser anterior a sus fines y objetivos. ${ }^{22}$ La idea es que la tradición kantiana que llega hasta Rawls ${ }^{23}$ y que concibe a los hombres como noúmenos ${ }^{24}$ despojados de una identidad comunitaria no permite reconocerlos como verdaderos actores morales. Esto solamente es posible a través del descubrimiento introspectivo de la comunidad particular que hay implícita en cada ser humano, con su también particular forma de concebir lo "bueno". Sin ello, la identidad de las personas aparece vaciada de sentido moral. ${ }^{25}$

\section{Crítica}

Para comenzar, no hay una justificación normativa de la preeminencia de la comunidad sobre los individuos. Parece evidente que los seres humanos se constituyen socialmente, pero de esta "socialización necesaria" no se sigue que la comunidad tenga ningún tipo de prius valorativo sobre los individuos. Sandel considera que la existencia de una comunidad "esencial" en la formación de la identidad individual y colectiva es razón suficiente para establecer su predominio valorativo. ${ }^{26}$ La falacia consiste en confundir cuestiones fácticas con normativas y pensar que el desarrollo social del individuo determina su estatus moral. Aun cuando se aceptara el carácter genético de las comunidades, dicho carácter no alcanza para descartar los límites que la defensa de los derechos individuales pueden ponerle a las distintas formas de persecución del "bien común" comunitario, ni tampoco para descartar el análisis moral que los individuos pueden hacer del contexto valorativo de esa comunidad bajo el examen de criterios universales.

MacIntyre directamente rechaza la distinción ser/deber ser del ideario moral moderno en virtud de un aristotelismo teleológico bastante difuso. ${ }^{27}$ Taylor intenta evitar esta falacia (pensar que ciertos presupuestos prescriptivos - ontológicos - tienen carácter normativo) dando fundamento moral a la red de integración solidaria y al contexto valorativo de la comunidad (a costa de los derechos individuales). ${ }^{28}$ Este autor afirma que el conjunto de facultades y virtudes características de los seres humanos no pueden ser desarrolladas en forma individual, sino necesariamente en un espacio social. Esas facultades y virtudes implican la adscripción a determinados deberes y derechos morales y jurídicos. El error de las teorías liberales es precisamente afirmar los derechos y las libertades individuales sin considerar su contrapartida: los deberes inherentes, porque precisamente se

${ }^{22}$ Ibid., pp. 15 y 54.

${ }^{23}$ Ibid., p. 14.

${ }^{24}$ Ibid., p. 2; C. Taylor, “The Diversity of Goods”, p. 230, así como A. MacIntyre, After Virtue, p. 89.

${ }^{25}$ M. Sandel, Liberalism and the Limits of Justice, p. 172.

${ }^{26}$ Ibid., pp. 146-153.

27 A. MacIntyre, After Virtue, p. 82.

${ }^{28}$ C. Taylor, "Atomism", p. 187. 
descuidan las condiciones socioestructurales del ejercicio de esos derechos. Esta tesis, llamada de las "condiciones sociales de la libertad" 29 y basada en una deducción hegeliana de deberes del concepto de libertad, sostiene que la existencia previa de una determinada matriz social es lo que permite la existencia de individuos autónomos con capacidad de autodeterminación moral. Ese ámbito social brinda el reconocimiento intersubjetivo e institucional adecuado para el desarrollo de esas facultades.

Sin embargo, el punto decisivo sigue siendo que la importancia de esta comunidad no sirve por sí misma para fundamentar su prioridad normativa $^{30}$ una vez alcanzada la autonomía moral del individuo. Precisamente, esa autonomía les permite a los individuos superar los niveles convencionales de desarrollo moral ${ }^{31}$ y dejar de ser meros atributos de la sustancia comunitaria. Por otra parte, si admitimos la posibilidad de la autonomía moral (liberal), debemos aceptar la preeminencia de los derechos individuales y, en consecuencia, la base deontológica de las teorías liberales. En caso contrario, deberíamos estar dispuestos a admitir que el horizonte normativo de la comunidad conforma un contexto sociocultural ya dado que resulta insuperable para los individuos y que, por lo tanto, está más allá del análisis moral basado en criterios universales. ${ }^{32}$ Esta imposibilidad de una distancia reflexiva de los individuos que quedan atrapados en el destino comunitario de su ethos ${ }^{33}$ implica abandonar una idea central de la autocomprensión y de la subjetividad moral. ${ }^{34}$ La crítica de nuestro entorno social y de nosotros mismos sería imposible porque el horizonte moral de nuestro ámbito no permite críticas fundadas en criterios normativos extraños a la comunidad. La única distancia admitida por el comunitarismo (Sandel y MacIntyre) es inmanente a la comunidad y está relacionada con una mejor comprensión de los papeles y las virtudes comunitarias preestablecidas. ${ }^{35}$ Aumentar esa distancia implica salir del ámbito comunitario, poner en peligro la identidad del actor moral y perseguir una representación incorrecta de la "buena vida". 36

Esa pequeña libertad admitida no significa ninguna clase de autonomía moral, porque la moralidad está reducida a cierta eticidad comunitaria y no hay ningún desarrollo independiente de la conciencia moral individual.

${ }^{29}$ Ibid., p. 209.

${ }^{30}$ Ibid., p. 206. Taylor habla de una "significant obligation to belong" [una importante obligación de pertenecer].

${ }^{31}$ Cfr. L. Kohlberg, Essays on Moral Development.

32 Otra consecuencia de esto sería el abandono de la idea de derechos humanos universales.

33 Véase A. MacIntyre, "Intelligibility, Goods and Rules", p. 664.

${ }^{34}$ Sobre esto, véase también la crítica de Will Kymlicka, "Liberalism and Communitarianism", pp. 181 y 192.

${ }^{35}$ Cfr. A. MacIntyre, After Virtue, p. 295. En sentido similar, M. Sandel, Liberalism and the Limits of Justice, pp. 57-179.

${ }^{36}$ M. Sandel, Liberalism and the Limits of Justice, p. 179. 
La participación del individuo en la formación de su propia identidad tiene que ver meramente con su adecuación a la comunidad sustancial ${ }^{37}$ para un mejor funcionamiento de la misma. Se trata de una adaptación consciente a los intereses y necesidades de la comunidad que perfecciona la socialización comunitaria del sujeto. ${ }^{38}$ Esa "socialización" no sólo se presenta como un "bien común" indiscutible, sino que se contrapone al atomismo extremo de las teorías liberales, aunque, en realidad, ninguna teoría liberal o deontológica pueda reducir al ser humano por completo a la forma de su existencia presocial y descartar la importancia de la socialización en la formación de la conciencia moral del individuo. Es imposible rechazar la importancia intrínseca que tiene la socialización e internalización de las formas convencionales de la moral para la formación de una conciencia individual autónoma, o negar que esa socialización se realiza en el contexto de un mundo-de-la-vida determinado. ${ }^{39}$ Pero esa socialización no debe concebirse como un límite al desarrollo moral del individuo, que debe adquirir la capacidad de analizar críticamente las suposiciones morales vigentes en su ámbito social. Ni la Teoría de la justicia ${ }^{40}$ ni la Teoría de la acción comunicativa, por ejemplo, parten de individuos desvinculados de su esfera social, ni tampoco pretenden dar fundamento moral al intercambio de intereses entre átomos individuales. ${ }^{41}$

\section{La función del contexto y lo contingente}

Problema: La teoría liberal considera que la base normativa de las comunidades puede ser examinada mediante normas éticas universales.

Tesis comunitarista: Es imposible fundamentar esas normas.

La idea central es que en cuestiones morales, las normas y los criterios deben basarse en una determinada comprensión colectiva de los problemas, que solamente se genera en el interior de una comunidad política concreta. Ningún principio universal ajeno a la comunidad puede reemplazar aquellas convicciones y supuestos implícitos derivados de compartir una determinada forma de vida común. ${ }^{42}$ Para MacIntyre, las fundamentaciones universalistas sólo pueden hacerse bajo la forma de decisiones. El

${ }^{37}$ Ibid., pp. 20, 150, 153, 179.

${ }^{38}$ Ibid., p. 180.

${ }^{39}$ Cfr. J. Habermas, "Individuierung durch Vergesellschaftung. George Herbert Meads Theorie der Subjektivität", p. 187.

40 Taylor excluye a Rawls del reproche del atomismo. Cfr. C. Taylor, "Legitimation Crisis?", p. 248.

${ }^{41}$ En este sentido, A. MacIntyre, "How Moral Agents Became Ghosts or Why the History of Ethics Diverged from that of the Philosophy of Mind", p. 295.

${ }^{42}$ Cfr. M. Walzer, Spheres of Justice, pp. 61 y 440. 
individuo debe guiarse por los papeles comunitarios que lo inscriben en una tradición local determinada. La búsqueda del propio bien guiada por una concepción de normas universales o derechos individuales, o aun la idea misma de autonomía del individuo, carece por completo de sentido y no permite fundar ningún contenido moral. La ontología comunitarista de MacIntyre no relativiza la función de los derechos y las libertades individuales por debajo de la noción de virtud, sino que directamente los descarta. ${ }^{43}$ En este sentido, el conjunto de derechos individuales no implica una racionalidad universal, dado que cualquier forma de racionalidad independiente de un contexto es imposible. Esos derechos apenas conforman una especie de tradición cultural, inconmensurable e intraducible, ${ }^{44}$ una línea narrativa que produce una concepción particular del mundo. El conflicto no aparece por la imposición de una forma racional universal, sino por la hegemonía cultural. ${ }^{45}$ Desde otra perspectiva, Rorty también afirma la imposibilidad de fundamentación de principios liberales universales, aunque no promueve el regreso a la "comunidad" en favor del abandono de la democracia liberal. La justificación de las instituciones liberales no puede recurrir a una especie de "metanarrativa" filosófica, sino que se constituye como un relato histórico originado en una tradición local. El reforzamiento de ese relato a través de la autocomprensión de la tradición como una comunidad de interpretación ${ }^{46}$ no significa que el contenido ético del Estado de derecho sea universal. De todos modos, esto no deviene en inestabilidad para las prácticas democráticas del Estado de derecho liberal porque precisamente esas prácticas están fundadas en la solidaridad y no en un criterio racional. ${ }^{47}$ La imposibilidad narrativa de justificación de las instituciones liberales se debe a la noción de contingencia del lenguaje, por la cual ni los juicios cognitivos ni los éticos logran escapar de la contingencia de los vocabularios locales que vuelven inaccesible todo metavocabulario. ${ }^{48}$

\section{Crítica}

En la teoría de las "esferas de la justicia", Walzer intenta probar la imposibilidad de un criterio normativo universalista de justicia distributiva.

43 Ibid., p. 98.

${ }^{44}$ Cfr. A. MacIntyre, Whose Justice?, Which Rationality?, p. 326.

45 Ibid., p. 183 y 402. En Three Rival Versions of Moral Inquiry: Enyclopedia, Genealogy, and Tradition, pp. 170 y 196, MacIntyre intenta demostrar la superioridad de la tradición tomista sobre la crítica "enciclopédica" realizada por la Ilustración y la tradición crítica "genealógica" que va desde Nietzsche hasta Foucault.

${ }^{46}$ Cfr. R. Rorty, "Pragmatism Relativism, and Irrationalism", p. 160.

47 Cfr. R. Rorty, Contingency, Irony and Solidarity, pp. 21 y 84. Esa solidaridad es una sensibilidad especial, una especie de "cultura estética" que produce identificación con el sufrimiento de otras personas.

${ }^{48}$ Ibid., p. 21. 
La tesis central es que una sociedad democrática debe restringir obligatoriamente ese criterio universal a los modos particulares de distribución de bienes. Cada bien social, de acuerdo con su sentido social, debe contar con su propio criterio de distribución independiente. El problema de esta teoría contextualista de los bienes es el establecimiento del sentido social de cada bien, que en última instancia determinará su forma particular de distribución. Si se acepta que los bienes sociales llevan en sí mismos sus propias reglas de distribución, establecidas por el sentido "social" que los sujetos le dan a esos bienes, no es posible fundar normas de justicia distributiva más que en la tradición particular de cada comunidad, es decir, en la "naturaleza de las cosas" o en una especie de "deber ser distributivo" emanado del "ser social" de los bienes, ${ }^{49}$ y este "deber ser" tendría que tener una pretensión moral de verdad.

El inconveniente de esta concepción de justicia distributiva es que no incluye la posibilidad de crítica de las formas de distribuir bienes en la comunidad. Si el sentido social de un bien (y por ende, su norma de distribución) surge de un proceso hermenéutico interno de la comunidad, derivado de ciertas prácticas contingentes ya existentes, la crítica de lo dado carece de posibilidad. Toda consideración procedimental crítica debe fundarse en reglas de distribución externas, ajenas a la tradición e incompatibles con una teoría contextualista de justicia distributiva. ${ }^{50}$ Considerar determinante una forma de vida específica y, sobre todo, su particular representación de la justicia y la moral a la hora de establecer el criterio de distribución de un bien, ${ }^{51}$ parece excluir toda posibilidad de hacer una crítica de ese criterio. ${ }^{52}$

Walzer intenta eludir esta reducción de las posibilidades críticas recurriendo a cierta racionalidad universal que el principio distributivo de cada bien debe tener necesariamente. La estructura básica de la justicia distributiva es contingente y está legitimada por la tradición local, ${ }^{53}$ pero debe respetar el significado inherente a cada bien social y a cada esfera distributiva. ${ }^{54}$ Dicho significado permite obtener inductivamente reglas de distribución para el bien social en cuestión, las cuales son racionales y su racionalidad radica en que deben ser globales y transhistóricas. ${ }^{55} \mathrm{~A}$ pesar del carácter localista y contingente de su teoría, el fundamento de la justicia sigue siendo un principio racional universal. Los vacíos que la "naturaleza de las cosas" deja en su camino son completados con contenidos

${ }^{49}$ Cfr. Michael Walzer, "Philosophy and Democracy", pp. 379-385.

${ }^{50}$ Cfr. J. Cohen, "Kommunitarismus und universeller Standpunkt".

${ }^{51}$ Cfr. M. Walzer, Spheres of Justice, p. 442.

${ }^{52}$ Cfr. S. Caney, "Liberalism and Communitarianism: A Misconceived Debate".

53 Ibid., p. 58.

${ }^{54}$ Ibid., p. 60.

${ }^{55}$ Ibid., p. 35. 
normativos de carácter universal. ${ }^{56}$ La justificación moral de las instituciones no resiste la reducción a la mera "eticidad" que surge de nuestra particular forma de comprensión de los bienes sociales. ${ }^{57}$ La concepción comunitaria de la "vida buena", o de lo que ésta debe ser, no sirve como marco de contención para los problemas relativos al establecimiento de normas de regulación justa de conflictos intersubjetivos, ni tampoco para los problemas relativos a la validez y la vigencia social de las normas. ${ }^{58}$ Aceptar el contexto limitante de la representación comunitaria de lo bueno para resolver estos problemas implica aceptar la contradicción de formular juicios morales no susceptibles de fundamentación universal, es decir, renunciar directamente al carácter crítico de la ética. ${ }^{59}$

El dilema comunitarista radica en aceptar que el ethos local está dado fuera de la órbita de la crítica moral, o bien, reducir la fuerza determinante de las tradiciones y de los shared understandings (acuerdos compartidos/entendimientos comunes) para dar lugar a contenidos normativos de carácter universal. MacIntyre se inclina por la primera de las soluciones; ${ }^{60}$ la idea liberal de los derechos individuales es rechazada en beneficio de la noción moral de virtud y de comunidad, a punto tal que cualquier fundamentación racional de esos derechos puede ser fácilmente reducida a argumentos destinados a conseguir acuerdos y consensos individuales. El verdadero consenso comunitario está implícito y se encuentra en la tradición heredada del ethos local. ${ }^{61} \mathrm{El}$ fomento de las virtudes permite desarrollar prácticas que sirven para establecer la unidad narrativa de las vidas individuales de los sujetos y para establecer los papeles cuya funcionalidad sirve a la reproducción de la comunidad. ${ }^{62}$ La tradición opera como criterio de corrección funcional de esas prácticas, pero ese criterio no es útil para oponer ninguna resistencia crítica a prácticas inmorales pero perfectamente funcionales para la comunidad. ${ }^{63}$ Se trata de un camino sin salida donde la crítica a la propia tradición está descartada de antemano. La ampliación de la solidaridad sólo puede darse a través del desarrollo de una cultura

${ }^{56}$ Cfr. R. Dworkin, "What Justice Isn't”, pp. 214-217.

${ }^{57}$ Ibid., p. 19.

${ }^{58}$ Cfr. J. Habermas, "Vom pragmatischen, ethischen und moralischen Gebrauch der praktischen Vernunft", p. 100.

${ }^{59}$ Véase E. Tugendhat, Vorlesungen über Ethik, p. 65.

${ }^{60}$ Sandel apela a la segunda opción al introducir en su concepción contingente de justicia distributiva un criterio normativo universal (corrección/incorrección moral). Cfr. M. Sandel, Liberalism and Its Critics, introducción, p. 6.

${ }^{61}$ Véase H. Schnädelbach, "Was ist Neoaristotelismus", pp. 6-25.

${ }^{62}$ Ibid., pp. 21-25.

63 Ibid., p. 23. También la noción de una "ley moral" (asimismo no universal), como instancia entre la praxis y la tradición (véase ibid., p. 24) permanece para MacIntyre supeditada a esta última. 
sensible al dolor y la crueldad, cuya base emotiva se encuentre inscrita en una determinada tradición local. ${ }^{64}$

\section{La función del "bien común"}

Problema: Las teorías liberales tradicionales dan prioridad a los derechos sobre las distintas concepciones de lo bueno.

Tesis comunitarista: Las libertades individuales y los principios de justicia política de carácter universal no deben imponer límites irrebasables a la búsqueda colectiva del "bien común".

Para el comunitarismo, lo intrínsecamente "bueno" se localiza en los procesos de "comunitarización" del individuo. Este proceso aparece como un fin en sí mismo y dependiente del "paradigma de la comunidad". ${ }^{65}$ Frente a la desintegración social, efecto de la imposición masiva de la cultura individualista propia del liberalismo, la única alternativa posible es revertir este fenómeno a través de una "comunitarización" de los sujetos. Se propone esta "vuelta a la comunidad" como un medio de integración primario en las actuales sociedades complejas frente a las formas de integración propuestas por el derecho y la moralidad, que deberían convertirse en una especie de eticidad comunitaria sustancial. No se trata aquí de una mera revitalización de las funciones integradoras de los grupos intermediarios y asociaciones pertenecientes a la dimensión de la sociedad civil, sino que la "estructura institucional básica" de la sociedad debe conformarse según la comunidad. ${ }^{66}$ MacIntyre directamente postula la necesidad de establecer un orden social cuya "estructura básica" se encuentre enmarcada por la tradición tomista. ${ }^{67}$ No sólo las instancias intermedias deben estar constituidas como una comunidad, sino que toda la sociedad debe regirse por el modelo de relaciones de la "situación ideal de familia". ${ }^{68}$ Las relaciones abstractas entre extraños (propias de la fragmentación individualista) sancionadas por el derecho y los principios morales deben ser reemplazadas por vínculos primarios - face to face-, relaciones fraternales, etc. ${ }^{69}$ Este reemplazo permitiría desplazar la justicia y los derechos individuales como mecanismos centrales de resolución de conflictos y de coordinación de la acción social en favor de la virtud. ${ }^{70}$ La cohesión de las comunidades

${ }^{64}$ Cfr. R. Rorty, Contingency, Irony and Solidarity, p. 305.

${ }^{65}$ En este punto, el comunitarismo coincide con el Critical Legal Studies Movement. Cfr. Richard W. Baumann, "The Communitarian Vision of Critical Legal Studies", p. 9.

${ }^{66} \mathrm{Cfr}$. M. Sandel, Liberalism and Its Critics, p. 173. Obviamente, la idea no se restringe precisamente a la conducta social de los individuos.

${ }^{67}$ Cfr. A. MacIntyre, Whose Justice?, Which Rationality?, p. 391.

${ }^{68}$ Cfr. M. Sandel, Liberalism and Its Critics, p. 173.

${ }^{69}$ Ibid., pp. 32 y 83.

${ }^{70}$ Ibid., pp. 31-32 y 169. 
no necesita (como las sociedades) la garantía de los mecanismos jurídicos para su reproducción, dado que la misma está asegurada a través de la persecución de un "bien común" colectivo. Este "bien común" se conforma a través de identidades y fines compartidos, tradiciones y ritos culturales heredados, asentimientos fraternales e intereses coincidentes. ${ }^{71}$ Los lazos comunitarios están reforzados por su carácter obligatorio, previo a cualquier elección del individuo y no como resultado de la misma. ${ }^{72}$ La integración no está dada por medios "artificiales" como normas jurídicas, derechos y obligaciones, sino por afectos y tradiciones compartidas. El pasado común que forma una auténtica "comunidad de memoria" colectiva define criterios de lealtad y compromiso ofreciendo una visión del mundo completa y abarcadora en la que el sujeto comunitario tiene un "lugar". ${ }^{73}$ En estos casos, la autocomprensión comunitaria nunca es problemática, porque el vocabulario común y el trasfondo implícito de prácticas y acuerdos da el marco ideal para contener posibles conflictos y para la formación de la identidad de los sujetos. La identificación de los miembros de una comunidad con su eticidad sustancial nunca está a discusión, como en el caso de las sociedades con Estados de derecho. ${ }^{74}$ La comunidad es un orden de convivencia basado en las relaciones de parentesco, vecindad y amistad, y, por supuesto, en un determinado "bien común". Precisamente, la comprensión colectiva de la necesidad de ese "bien común" vuelve innecesario el derecho. Sólo la comprensión mutua une a los miembros de la comunidad en una armonía social reforzada por la costumbre, la religión, la cultura y el pasado común. Frente a esto, la "sociedad liberal" parece un mero agregado de individuos unidos por un sistema de derechos y libertades individuales que se dedican solamente al intercambio sin persecución de ningún "bien común" en particular que los vincule internamente. ${ }^{75}$ Por este motivo, Sandel cree que las sociedades liberales, cuyos mecanismos de integración son predominantemente jurídicos, deben adaptarse a las premisas comunitarias y a la determinación de un "bien común" colectivo para poder subsistir. ${ }^{76}$

\section{Crítica}

La "comunitarización" como un "bien común" es una de las premisas indiscutibles del comunitarismo, porque sin ella es imposible alcanzar el grado

${ }^{71}$ Cfr. A. MacIntyre, Whose Justice? Which Rationality?, p. 67.

${ }^{72}$ Cfr. M. Sandel, Liberalism and Its Critics, p. 150, y A. MacIntyre, After Virtue, p. 294.

${ }^{73} \mathrm{Cfr}$. R. Bellah et al., Habits of the Heart, p. 185.

${ }^{74}$ Cfr. M. Sandel, Liberalism and Its Critics, p. 172.

75 F. Tönnies, Gemeinschaft und Gesellschaft, Libro 1, §§ 1, 6, 9, 19, 25; Libro 3, § 4; § 1, pp. $1,12,17,20,35,44,153$ у 207.

${ }^{76}$ Cfr. M. Sandel, Liberalism and Its Critics, p. 183. 
de homogeneidad necesario para la reproducción de la comunidad. Sin embargo, el proceso de "re-comunitarización" de las sociedades complejas (para detener la desintegración social) resulta problemático porque no es posible esperar que el retroceso del derecho provoque de manera espontánea un aumento de homogeneidad. Cualquier política de homogeneización comunitaria debe producir mecanismos de exclusión simbólicos o reales. Estos mecanismos deben estar diseñados para "integrar" a aquellas minorías culturales ajenas a la "comunidad sustancial" que deben modificar su forma de vida con el fin de poder homogeneizarse con la mayoría. En este sentido, la "comunitarización" forzada como principio de ordenación social sólo puede llevarse a cabo a través de prácticas directas de exclusión social. ${ }^{77} \mathrm{El}$ derecho debe adaptarse para llenar sus normas con los contenidos morales comunitarios en vigencia sin recurrir a criterios universales o fundamentos procedimentales. La validez del derecho depende precisamente de su eficacia en la realización de esos contenidos morales que son los "bienes constitutivos" de la comunidad y que resultan fundamentales para el mantenimiento de su forma tradicional de vida. ${ }^{78}$ La protección jurídica de esferas privadas de libertad debe descartarse en favor de la protección de ciertos valores dominantes. ${ }^{79}$ La política de derechos debe ser sustituida por una política de "bien común" que proteja los valores comunes (shared values) a la comunidad, aun a costa de las minorías y los individuos. ${ }^{80}$

El interés racional de las personas como punto de partida para la creación de normas es rechazado por estar fundado en una concepción metafísica de los individuos como entes aislados con valor propio. Las bases teóricas individualistas del derecho liberal deben ser reemplazadas por un derecho comunitario ${ }^{81}$ en el que la comunidad se comprende como una especie de metapersona a la que el individuo le debe su identidad, su cultura y su comprensión del mundo. Y por esto, los daños sufridos en la persecución de los fines comunitarios no son verdaderos sacrificios, dado que vive su vida como un auténtico agente de esa comunidad. La restricción de las libertades individuales no implica que el sujeto sufra un menoscabo, porque la comunidad lo compensa con un verdadero mundo-de-la-vida, no mediado por la racionalidad instrumental de otros subsistemas. ${ }^{82}$ Según el comunitarismo, el ámbito de actuación individual debe restringirse a la sa-

77 Cfr. H.N. Hirsch; "The Threnody of Liberalism. Constitutional Liberty and the Renewal of Community", pp. 423-435.

${ }^{78}$ Autores como Devlin y Stephen sostuvieron una ontología conservadora de la comunidad muy similar. Cfr. H.L.A. Hart, Law, Liberty and Morality, especialmente pp. 48-69.

${ }^{79}$ Cfr. P. Selznick, "Dworkin's Unfinished Task".

${ }^{80} \mathrm{Cfr}$. M. Friedman, "Feminism and Modern Friendship: Dislocating the Community", p. 275.

${ }^{81}$ Cfr. M. Sandel, Liberalism and Its Critics, p. 151.

82 Ibid., p. 143. 
tisfacción ética de ciertos criterios de pertenencia. ${ }^{83} \mathrm{~A}$ la restricción de los ámbitos de libertad y de pluralidad de las sociedades modernas, debemos sumar la "consideración" comunitaria de los individuos que va a estar regida por su aporte a la forma de vida específica de la comunidad. La forma en que los individuos persigan su ideal de "vida buena" va a ser juzgada en función de su contribución a los propios fines comunitarios y bienes comunes. La disposición de los individuos a realizar y perseguir esos fines es la medida que las comunidades pueden usar para valorar socialmente a las personas en cuanto miembros de la comunidad. ${ }^{84}$ La valoración de formas de vida particulares y convicciones personales es sacrificada en aras del respeto desigual del merecimiento comunitario. ${ }^{85}$

Para la revitalización de las comunidades, la postura comunitarista exige rechazar o al menos relativizar la idea de un derecho basado en los derechos individuales destinados a generar un reconocimiento igualitario de las personas. Sin embargo, el abandono del pluralismo cultural de las sociedades modernas se debe realizar en función de los valores de una comunidad cuya "estructura básica" nunca es demasiado explícita en el pensamiento comunitarista ${ }^{86}$ y cuyo poder de convicción normativo es difuso. ${ }^{87}$ La idea de gobernar regida sólo por la realización de un "bien común" en una sociedad de valores compartidos trae aparejados algunos problemas. ${ }^{88}$ Las sociedades modernas han alcanzado un nivel tan alto de pluralidad y diversidad de formas de vida, a veces contrapuestas, que la idea de establecer un "bien común" colectivo que rija el ordenamiento social a través de un derecho comunitario y basado en una identidad común parece una ingenuidad, o bien, una idea totalitaria del funcionamiento de las comunidades. Esta diferenciación social provoca que todo intento de reconvertir las formas de integración del derecho moderno en una integración basada en un derecho conformado a partir de valores sustanciales comunitarios sólo pueda significar la reducción de la pluralidad y de la riqueza de los diferentes mundos de vida. Forzar la integración de minorías, obligar al abandono de prácticas culturales diferentes, limitar la multiplicidad de prácticas e instituciones sociales, aceptar un esquema de valores uniforme, adoptar un derecho conformado por valoraciones vigentes - usos y costumbres- sin tomar en cuenta razones procedimentales o morales, parece ser la política del "bien común". Política realizada en honor de una comunidad sustancial que paradójicamente le permitiría vivir a los individuos una vida ética. Unidad, armonía social y coincidencia en el interés político de perseguir

${ }^{83}$ Cfr. A. MacIntyre, After Virtue, p. 294.

${ }^{84}$ Cfr. A. Honneth, Kampf um Anerkennung, p. 197.

${ }^{85}$ Véase A. MacIntyre, After Virtue, p. 334.

${ }^{86}$ Cfr. S. Holmes, "The Permanent Structure of Antiliberal Thought", p. 227.

${ }^{87}$ Cfr. D.L. Phillips, Looking Backward. A Critical Appraisal of Communitarian Thought.

${ }^{88}$ Cfr. M. Sandel, Liberalism and Its Critics, p. 183. 
ese "bien común" a costa de la democracia misma. Los significados sociales compartidos y las comprensiones básicas comunes no son más que una excusa para excluir y eventualmente discriminar la diferencia.

¿De qué otra manera es posible alcanzar la armonía unitaria en una comunidad en cuyo seno conviven otras comunidades minoritarias (minorías culturales, étnicas, sexuales, etc.), si no es en el marco de intermediación de un derecho basado en normas independientes del contexto? Si el orden moral de cada comunidad supone la identificación con su tradición particular, el entendimiento y el consenso entre culturas diferentes es imposible sin el derecho. Sin la regulación del sistema de derechos, el conflicto de valores en las relaciones intercomunitarias puede ser resuelto mediante la tolerancia, el mero intercambio de intereses (mercado) y, en el peor de los casos, el predominio de la cultura dominante o el enfrentamiento directo. ${ }^{89}$ Sin los mecanismos jurídicos de regulación de conflictos, ni los procedimientos deliberativos de la democracia para alcanzar consenso, las distintas concepciones del mundo pueden excluirse mutuamente ad infinitum. Cada comunidad es transformada en un ideal que arrasa con todo, y se establece una continuidad imaginaria entre la tradición y la homogeneidad en los intereses de sus miembros, entre "bien común" y autogobierno democrático, y entre la propia comunidad y el ideal participativo. El carácter negativo de los derechos individuales es rechazado por la virtud republicana del ciudadano activo. Pero la relación de implicación entre eticidad comunitaria y democracia participativa resulta inexplicable, dado que los ciudadanos han renunciado a casi toda su autonomía individual en pro de la integración comunitaria. ${ }^{90}$

La democracia en la comunidad no surge a través de procedimientos cooperativos o construcción deliberativa de consensos, sino de la asunción introspectiva de la sustancia ética de la comunidad. El consenso se alcanza mediante la identificación de los individuos y sus intereses con el símbolo colectivo de la comunidad. ${ }^{91}$ La deliberación es sencillamente descartada por superflua e innecesaria. Si la participación "comunitarista" demanda previamente la homogeneización de los participantes con la sustancia ética de la comunidad, difícilmente se puede hablar de democracia y mucho menos de crítica democrática a esa eticidad comunitaria. ${ }^{92}$ Para MacIntyre, la discusión pública directa carece de sentido porque la comunidad no puede poner en juego su identidad por cuestionamientos de sus miembros. Éste es el punto débil del sistema de derechos individuales: que garantiza las condiciones de esa discusión, pero que, precisamente a causa de ello, no puede establecer una comunidad moral sustancial de acuerdo con la tradición de

${ }^{89}$ Cfr. W. Aubert, "Competition and Dissensus", p. 26.

${ }^{90}$ Véase G. Kateb, "Democratic Individuality and the Meaning of Rights", p. 183.

${ }^{91}$ Cfr. B. Barber, Strong Democracy. Participatory Politics for a New Age, p. 142.

${ }^{92}$ Cfr. M. Sandel, Liberalism and Its Critics, p. 151. 
las virtudes. ${ }^{93}$ Sin embargo, el comunitarismo no explica la forma en que estas difusas normas morales sustantivas pueden reemplazar la flexibilidad y predecibilidad del derecho y detener el proceso de desintegración social. ${ }^{94}$ La idea de que en las sociedades occidentales con mecanismos funcionales estratificados de diferenciación, la inclusión de los individuos en "la sociedad" pueda realizarse sin ayuda del sistema de derechos, exclusivamente a través de los sistemas valorativos o morales vigentes, ${ }^{95}$ parece irrealista y nuevamente ingenua. ${ }^{96}$ La democracia de masas ya no puede ser una sociedad integrada meramente por una orientación homogénea de valores, ni tampoco el consenso comunitario metapolítico de todos los ciudadanos puede organizarse como una "religión civil". ${ }^{97}$ La diferenciación ha alcanzado tal grado de complejidad que la cohesión social no puede depender solamente de las convicciones valorativas compartidas por los ciudadanos. Se requiere un mecanismo de reducción de esa complejidad que pueda garantizar, aunque sea en téminos formales y abstractos, la integración de los individuos. La autorreproducción social no depende solamente del mantenimiento de determinadas estructuras simbólicas de formas de vida comunitarias. La sociedad también se organiza mediante procesos sistémicos diferenciados. ${ }^{98}$ Esto significa que la mera estabilización y unidad propuesta por las identidades colectivas no es suficiente para resolver los problemas de coordinación funcional de la integración social. ${ }^{99}$ Los valores no alcanzan para reemplazar al derecho, al menos en lo que se refiere a la integración y la cohesión social. Las normas sociales sin ningún tipo de control procedimental que se generan espontáneamente en una sociedad no pueden sustituir al derecho como sistema diferenciado de otros sistemas normativos en sus funciones de control social. En este sentido, la presión social ejercida por la moral comunitaria no alcanza.

Para el comunitarismo, los derechos individuales atentan contra la comunidad no solamente a través de su lógica universalizadora, sino también porque le permiten al sujeto alejarse del horizonte valorativo común. La conversión del derecho liberal en derecho comunitario se da mediante la deducción de conceptos jurídicos a partir de valores de la moral local. El control racional de los conceptos y normas jurídicas debe dar lugar a una legislación simbólica que exprese y realice los valores sustantivos de

93 Cfr. A. MacIntyre, After Virtue, p. 335-339.

${ }^{94}$ El significado fuerte que Hegel otorga a las nociones de derecho abstracto, de persona jurídica y de racionalidad de la igualdad general de la ley es sistemáticamente ignorado. $C f r$. G.W.F. Hegel, Grundlinien der Philosophie des Rechts, Werke, vol. 1, §§ 34 у 209, pp. 92 у 361.

${ }^{95}$ Cfr. N. Luhmann, Soziologische Aufklärung, pp. 94 y 188.

${ }^{96}$ Véase U. Beck y Elisabeth Beck-Gemsheim, "Individualisierung in modernen Gesellschaften", p. 10.

97 Véase R. Bellah et al., Habits of the Heart, p. 255, y The Good Society, p. 179.

98 Cfr. J. Habermas, Theorie des kommunikativen Handelns, vol. 2, p. 226.

${ }^{99}$ Cfr. B. Peters, Die Integration moderner Gesellschaften, pp. 92 y 229. 
la comunidad. ${ }^{100} \mathrm{El}$ problema habitual es la vaguedad e indeterminación de esos valores comunitarios que, excluida la racionalidad procedimental, deben ser la base de la legislación en la comunidad. Por otra parte, si se acepta un derecho comunitario en desmedro de los derechos individuales, las decisiones judiciales se adelantarían a la articulación racional que toda legislación impone, al filtrar a su interior las valoraciones propias de las comunidades sustanciales. Esta idea del derecho está pensada como una forma de organización de lo político que limita dicho ámbito a las formas rígidas de la autoadministración local. La desvalorización de la esfera política como un ámbito común donde discutir y criticar las preferencias arbitrarias locales sólo puede ser entendida como una pérdida directa para el ámbito de acción libre y democrático del individuo y de la sociedad. En este caso, sólo el derecho y su lógica universal puede garantizar la esfera pública y la adecuada protección de los individuos contra el avance de la comunidad. Un derecho neutral frente a las diferentes concepciones de la "vida buena" puede establecer las condiciones adecuadas para el desarrollo de la pertenencia social y de la identidad individual. ${ }^{101}$ Precisamente, la noción formal y abstracta de "persona de derecho" protege las diferentes identidades morales ${ }^{102}$ y les da a los individuos la garantía jurídica de su libertad personal. Esta libertad que abre las comunidades a extraños les permite a los individuos buscar la comunidad de su preferencia evitando los riesgos totalitarios de una "comunitarización" forzosa (tanto de la propia comunidad como de otra). El Estado de derecho a través de su sistema de libertades individuales pretende garantizar (aun en términos abstractos y formales) las formas básicas de reconocimiento de las personas en cuanto tales. Este reconocimiento protege a los individuos y les permite abandonar sus comunidades y entrar a formar parte de otras nuevas. ${ }^{103}$ La elección libre y autónoma de una comunidad le brinda un carácter normativo distinto del de las tradiciones heredadas sin consentimiento de las personas.

\section{Observaciones finales}

La sustitución de una "política de los derechos" por una "política del bien común" del comunitarismo pretende reemplazar una concepción jurídica basada en los derechos individuales por otra cuya finalidad es la realización de la vida buena, tal como la considere la comunidad. Este reemplazo serviría para revertir el proceso de desintegración social, porque los individuos pertenecientes a comunidades constitutivas integradas alrededor de

\footnotetext{
${ }^{100}$ Cfr. A. Etzioni, The Spirit of Community, p. 81.

${ }^{101}$ Véase A.E. Buchanan, "Assessing the Communitarian Critique of Liberalism", pp. 852, 858 y 867.

102 Cfr. R. Forst, Kontexte der Gerechtigkeit, p. 113.

${ }^{103}$ Véase J. Waldron, "When Justice Replaces Affection: The Need for Rights”, p. 370.
} 
valores morales fuertes defenderían "naturalmente" sus vínculos y lealtades locales del avance del principio formal de igualdad ante la ley y de otras normas abstractas surgidas del derecho. ${ }^{104} \mathrm{Al}$ mismo tiempo, este derecho debe ser rechazado por la solidaridad comunitaria en virtud de un derecho basado en usos y costumbres que, a largo plazo, sea el encargado de imponer a las minorías la adopción de la identidad "comunitaria" de las mayorías que demandan la unidad, la homogeneidad y la cohesión social de la comunidad. ${ }^{105}$

Por otra parte, la insistencia comunitarista en que los vínculos de la comunidad deben ser previos y no pueden ser elegidos ${ }^{106}$ se opone directamente a toda forma de relación comunitaria compatible con una sociedad compleja, con el pluralismo y la diferencia, marco donde residen las verdaderas fuentes de la solidaridad moderna. Si bien es cierto que se puede constatar la desaparición de algunas formas típicas de solidaridad (síntoma de desintegración social para el comunitarismo), también han aparecido otras nuevas. Se trata de solidaridades puntuales, restringidas en el tiempo y limitadas a un aspecto del individuo. No relacionan para toda la vida a una persona, sino que dan libertad de cambio o reformulación del compromiso original. Esta solidaridad libremente elegida y no compulsiva, como la de las sociedades premodernas (Gemeinschaften), brinda al individuo la posibilidad de renovar el lazo si las relaciones sociales establecidas corresponden a sus deseos. ${ }^{107}$ Estas formas débiles de solidaridad están marcadas por la autonomía del individuo, que decide entrar a la comunidad y permanecer en ella. El pasaje de la comunidad a la sociedad como marco para las relaciones sociales también ha tenido un efecto de "cosmopolitización". Mientras que en las comunidades premodernas, los individuos ajenos a la comunidad eran vistos como extraños y posibles enemigos, la socialización moderna, el aumento de la población y la consiguiente aparición de la sociedad de masas han provocado la desaparición de esas formas tradicionales de exclusión. En la actualidad, la vida social de las personas está poblada de "extraños" que es imposible excluir y han pasado a convertirse solamente en "alguien a quien no conozco". ${ }^{108}$ Esta superación de los particularismos, de las relaciones regionales a favor de una dimensión más abarcadora, pluralista y universal, probablemente se deba al surgimiento del Estado-nación ${ }^{109}$ en el siglo XIX, e implica un

${ }^{104}$ Cfr. la más moderada posición de Philip Selznick, en The Moral Commonwealth. Social Theory and the Promise of Community, p. 193.

105 Cfr. W. Kymlicka, Contemporary Political Philosophy, p. 228.

${ }^{106}$ Cfr., sobre todo, M. Sandel, Liberalism and Its Critics, p. 149; A. MacIntyre, After Virtue, p. 293.

107 Véase A. Giddens, The Consequences of Modernity.

108 Ibid.

${ }^{109}$ Cfr. T. Pinkard, "Neo-Hegelian Reflections on the Communitarian Debate", en Michael Walzer, Toward a Global Civil Society, p. 122. 
grado de integración social abstracto, pero no por eso menos importante o con menos consecuencias para las relaciones sociales de los individuos. ${ }^{110}$ El proceso moderno de individualización no implica inevitablemente una reducción del compromiso social expresado en la solidaridad. Por el contrario, el compromiso forzado de la comunidad puede ganar en libertad, espontaneidad y diversidad. ${ }^{111}$ El reemplazo de los criterios tradicionales de interrelación de la comunidad por una forma de socialización que permite al individuo elegir libremente y en forma autónoma su participación genera una estructura abierta de relaciones sociales. La reproducción de esa estructura social sólo es posible mediante un sistema jurídico orientado a la protección de las libertades individuales. ${ }^{112}$

\section{BIBLIOGRAFÍA}

Aubert, Wilhelm, "Competition and Dissensus: Two Types of Conflict and Conflict Resolution", Journal of Conflict Resolution, vol. 7, 1963, pp. 26-32.

Barber, Benjamin, Strong Democracy. Participatory Politics for a New Age, University of California Press, Berkeley, 1984.

—-, The Conquest of Politics, Princeton University Press, Princeton, 1988.

Baumann, Richard W., "The Communitarian Vision of Critical Legal Studies", en A.C. Hutchinson y L.J.M. Green (comps.), Law and Community. The End of Individualism?, pp. 6-23.

Beck, Ulrich y Elisabeth Beck-Gemsheim, "Individualisierung in modernen Gesellschaften", en Riskante Freiheiten, pp. 10-39.

- (comps.), Riskante Freiheiten, Suhrkamp, Fráncfort, 1994.

Bellah, Robert et al., The Good Society, Knopf Press, Nueva York, 1991.

— , Habits of the Heart, University of California Press, Berkeley, 1985.

Benhabib, Sheila, "Autonomy, Modernity, and Community. Communitarianism and Critical Social Theory in Dialogue", en A. Honeth (comp.), Zwischenbetrachtungen im Prozeß der aufklärung. Jürgen Habermas zum 60. Geburstag, Suhrkamp, Fráncfort del Meno, 1989, pp. 373-385.

Blair, Tony, New Britain: My Vision of a Young Country, Macmillan, Londres, 1996.

Bowring, Finn, "Communitarianism and Morality: In Search of the Subject", New Left Review, no. 222, marzo-abril de 1997, pp. 93-113.

Buchanan, Allen E., "Assessing the Communitarian Critique of Liberalism", Ethics, vol. 99, no. 4, 1989, pp. 852-882.

Caney, Simon, "Liberalism and Communitarianism: A Misconceived Debate", Political Studies, vol. XL, 1992, pp. 273-289.

Cohen, Joshua, "Kommunitarismus und universeller Standpunkt", Deutsche Zeitschrift für Philosophie, vol. 41, 1993, pp. 1009-1015.

Dworkin, Ronald, Laws Empire, Belknap, Londres, 1991.

${ }^{110}$ Cfr. J. Habermas, "Der europäische Nationalstaat — Zur Vergangenheit und Zukunft von Souveranität und Staatsbürgerschaft", pp. 128-153.

${ }^{111}$ K.-O. Hondrich y C. Koeh-Arzberger, Solidarität in der modernen Gesellschaft, p. 20.

112 H. Keupp, "Ambivalenzen postmoderner Identität", p. 336. 
Dworkin, Ronald, "Liberal Community”, California Law Review, 1989, vol. 77, no. 3, pp. 479-502.

_-, "What Justice Isn't", A Matter of Principle, Harvard University Press, Cambridge, 1985, pp. 214-220.

Etzioni, Amitai, The Spirit of Community, The Free Press, Nueva York, 1993.

- (comp.), New Communitarian Thinking, University of Virginia Press, Charlottesville, 1995.

Forst, Rainer, Kontexte der Gerechtigkeit, Suhrkamp, Fráncfort del Meno, 1994.

Friedman, Marylin, "Feminism and Modern Friendship: Dislocating the Community", Ethics, vol. 99, no. 2, 1989, pp. 275-290.

Giddens, Anthony, The Consequences of Modernity, Polity Press, Cambridge, 1991.

Gutmann, Amy, "Communitarian Critics to Liberalism", Philosophy and Public Affairs, vol. 14, no. 3, 1985, pp. 308-322.

Habermas, Jürgen, "Der europäische Nationalstaat — Zur Vergangenheit und Zukunft von Souveranität und Staatsbürgerschaft", Die Einbeziehung des Anderen, Suhrkamp, Fráncfort, 1999, pp. 128-153.

—_, Faktizität und Geltung, Suhrkamp, Fráncfort del Meno, 1992.

__, "Individuierung durch Vergesellschaftung. George Herbert Meads Theorie der Subjektivität", Nachmetaphysisches Denken, Suhrkamp, Fráncfort, 1992, pp. 187-241.

_- Theorie des kommunikativen Handelns, Suhrkamp, Fráncfort del Meno, 1981, 2 vols.

_- "Vom pragmatischen, ethischen und moralischen Gebrauch der praktischen Vernunft”, Erläuterungen zur Diskursethik, Suhrkamp, Fráncfort del Meno, 1989, pp. 100-118.

Hart, H.L.A., Law, Liberty and Morality, Stanford University Press, Stanford, 1963.

Hegel, G.W.F., Grundlinien der Philosophie des Rechts, Suhrkamp, Fráncfort del Meno, 1986, Werke, vol. 1.

Hirsch, H.N., "The Threnody of Liberalism. Constitutional Liberty and the Renewal of Community", Political Theory, vol. 14, no. 3, 1986, pp. 423-449.

Holmes, Stephen, "The Permanent Structure of Antiliberal Thought", en N. Rosenblum (comp.), Liberalism and the Moral Life, p. 227-253.

Hondrich, Karl-Otto y Claudia Koeh-Arzberger, Solidarität in der modernen Gesellschaft, Suhrkamp, Fráncfort del Meno, 1992.

Honneth, Axel, "Individualisierung und Gemeinschaft", en C. Zahlman, Kommunitarismus in der Diskussion, pp. 16-23.

—_, Kampf um Anerkennung, Suhrkamp, Fráncfort del Meno, 1992.

Hutchinson, Allan C. y Leslie J.M. Green (comps.), Law and Community. The End of Individualism?, Toronto University Press, Toronto, 1989.

Kallscheuer, Otto, "Kommunitarismus? Anregungen zum weiterlesen", en C. Zahlman (comp.), Kommunitarismus in der Diskussion, pp. 124-151.

Kateb, George, "Democratic Individuality and the Meaning of Rights", en N. Rosenblum (comp.), Liberalism and the Moral Life, pp. 183-206.

Keupp, Heiner, "Ambivalenzen postmoderner Identität", en U. Beck y E. BeckGernsheim (comps.), Riskante Freiheiten, pp. 336-350.

Kohlberg, Lawrence, Essays on Moral Development, Harper and Row, Cambridge, 1981. 
Kymlicka, Will, Contemporary Political Philosophy, Clarendon Press, Oxford, 1990.

_- "Liberalism and Communitarianism", Canadian Journal of Philosophy, vol. 18, no. 2, 1988, pp. 181-203.

Luhmann, Niklas, Soziologische Aufklärung, Leske und Budrich, Opladen, 1981.

MacIntyre, Alasdair, After Virtue, Notre Dame University Press, Notre Dame, 1981.

— - "How Moral Agents Became Ghosts or Why the History of Ethics Diverged

from that of the Philosophy of Mind", Synthese, 1982, vol. 53, pp. 295-312.

_-, "Intelligibility, Goods and Rules", Journal of Philosophy, vol. 79, 1982, pp. 663-665.

- Three Rival Versions of Moral Inquiry: Enyclopedia, Genealogy, and Tradition, Notre Dame University Press, Notre Dame, 1990.

_- Whose Justice?, Which Rationality?, Macmillan, Londres, 1988.

Michelmann, Frank, "Laws Republic", The Yale Law Journal, vol. 97, 1988, pp. 1490-1531.

Peters, Bernhard, Die Integration moderner Gesellschaften, Suhrkamp, Fráncfort del Meno, 1993.

—-, Rationalität, Recht und Gesellschaft, Suhrkamp, Fráncfort, 1991.

Phillips, Derek L., Looking Backward. A Critical Appraisal of Communitarian Thought, Princeton University Press, Princeton, 1993.

Pinkard, Terry, "Neo-Hegelian Reflections on the Communitarian Debate", en M. Walzer, Toward a Global Civil Society, pp. 114-126.

Reese-Schäfer, Walter, Was ist Kommunitarismus, Suhrkamp, Fráncfort del Meno, 1994.

Rorty, Richard, Contingency, Irony and Solidarity, Cambridge University Press, Cambridge, 1989.

—_, "Pragmatism, Relativism, and Irrationalism", Consequences of Pragmatism, Haruester, Brighton, 1982, pp. 160-175.

Rosenblum, Nancy (comp.), Liberalism and the Moral Life, Harvard University Press, Cambridge, 1989.

Sandel, Michael, Liberalism and Its Critics, Cambridge University Press, Cambridge, 1984.

—- Liberalism and the Limits of Justice, Cambridge University Press, Cambridge, 1982.

Schnädelbach, Herbert, "Was ist Neoaristotelismus", Information Philosophie, vol. 14, no. 1, febrero de 1986, pp. 6-25.

Selznick, Philip, “Dworkin's Unfinished Task”, California Law Review, vol. 77, 1989, pp. 505-513.

- The Moral Commonwealth. Social Theory and the Promise of Community, University of California Press, Berkeley, 1992.

Sunstein, Cass R., "Beyond the Republican Revival", The Yale Law Journal, vol. 97, 1988, pp. 1532-1550.

Taylor, Charles, "Atomism", en Philosophical Papers, vol. II, pp. 182-209.

—-, Hegel and Modern Society, Cambridge University Press, Cambridge, 1979.

__, "Legitimation Crisis?", Philosophical Papers, vol. II, pp. 248-288.

—, Philosophical Papers, Cambridge University Press, Cambridge, vol. I, 1985; vol. II, 1989.

—_, "Self-Interpreting Animals", Philosophical Papers, vol. I, pp. 45-76. 
Taylor, Charles, Sources of the Self: The Making of the Modern Identity, Cambridge University Press, Cambridge, 1989.

_- "The Diversity of Goods", Philosophical Papers, vol. II, pp. 220-270.

—_, "What Is Human Agency?", en Philosophical Papers, vol. I. pp. 9-28.

Tönnies, Ferdinand, Gemeinschaft und Gesellschaft, Wissenschaftliche Buchgesellschaft, Darmstadt, 1991.

Tugendhat, Ernst, Vorlesungen über Ethik, Suhrkamp, Fráncfort del Meno, 1995.

Turner, Bryan y Peter Hamilton, Citizenship, Routledge and Kegan, Londres, 1994, vol. II.

Waldron, Jeremy, "When Justice Replaces Affection: The Need for Rights", Liberal Rights. Collected Papers 1981-1991, Cambridge University Press, Cambridge, 1993, pp. 370-391.

Walzer, Michael, "Civility and Civic Virtue in Contemporary America", en B. Turner y P. Hamilton, Citizenship, vol. II, pp. 176-187.

- Obligations. Essays on Disobedience, War and Citizenship, Harvard University Press, Cambridge, 1970.

__ "Philosophy and Democracy", Political Theory, vol. 9, no. 3, 1981, pp. 379399.

—-, Spheres of Justice, Clarendon Press, Oxford, 1983.

— Toward a Global Civil Society, Berghahn, Providence, 1995.

Zahlman, Christel (comp.), Kommunitarismus in der Diskussion, Rotbuch, Berlín, 1992.

Recibido: 27 de mayo de 2002; aceptado el 4 de febrero de 2003 